\title{
Evidence of biological efficacy for prolonged glucocorticoid treatment in patients with unresolving ARDS
}

\author{
G.U. Meduri, P. Carratu, A.X. Freire
}

Evidence of biological efficacy for prolonged glucocorticoid treatment in patients with unresolving ARDS. G. U. Meduri, P. Carratu, A.X. Freire. (C) ERS Journals Ltd 2003. ABSTRACT: Acute respiratory distress syndrome (ARDS) is a disease of multifactorial etiology characterised by rapid development of severe diffuse and nonhomogenous inflammation of the pulmonary lobules causing life-threatening hypoxaemic respiratory failure. The current authors tested a therapeutic intervention on a previously defined pathophysiological model of ARDS. The model was defined by investigating, during the natural history of ARDS, the relationship among the three fundamental elements of a disease process pathogenesis, structural alterations, and functional consequences. In these studies, the present authors provided biological and morphological evidence indicating that ARDS patients failing to improve after 1 week of mechanical ventilation (unresolving ARDS) have intense and protracted (dysregulated) pulmonary and systemic inflammatory and neo-fibrogenetic activity.

Nuclear factor- $\mathrm{KB}$ and the glucocorticoid receptor have diametrically opposed functions in regulating inflammation. This chapter will review recent data indicating that poor outcome in acute respiratory distress syndrome might be related in part to failure of the activated glucocorticoid receptors to downregulate the transcription of inflammatory cytokines despite elevated levels of circulating cortisol. In a small randomised study of patients with unresolving acute respiratory distress syndrome, the current authors have shown that prolonged glucocorticoid supplementation improved all aspects of glucocorticoid receptors function and enhanced glucocorticoid-mediated antiinflammatory action by interfering with nuclear factor- $\mathbf{B}$ activation.

Eur Respir J 2003; 22: Suppl. 42, 57s-64s.
Memphis Lung Research Program, Dept of Medicine, Pulmonary and Critical Care Division, The University of Tennessee Health Science Center, Memphis, Tennessee, USA.

Correspondence: G.U. Meduri, University of Tennessee Health Science Center, Division of Pulmonary and Critical Care Medicine, 956 Court Avenue, Room H316, Memphis, TN 38163, USA

Fax: 9014487726

E-mail: umeduri@utmem.edu

Keywords: Acute respiratory distress syndrome biology

glucocorticoid

glucocorticoid receptor

nuclear factor- $\kappa \mathrm{B}$

outcome

This work was supported by the Baptist Memorial Health Care Foundation and the Assisi Foundation of Memphis.
Acute respiratory distress syndrome (ARDS) is a term applied to a clinical condition of multifactorial etiology associated with a relatively specific morphological lesion termed "diffuse alveolar damage" [1]. This chapter will review studies that have tested a therapeutic intervention (glucocorticoid (GC) treatment) on a previously defined pathophysiological model of ARDS [2]. The model was developed by investigating during the longitudinal course of ARDS, the relationship between the three fundamental elements of a disease process pathogenesis, structural alterations, and functional consequences [3].

At presentation, (early) ARDS manifests with severe, diffuse, and nonhomogenous acute host inflammatory response (HIR) of the pulmonary lobules leading to a breakdown in the barrier and gas exchange function of the lung. Injury to the alveolo-capillary membrane (ACM) causes flooding of the airspaces with protein-rich neutrophilic oedema fluid, resulting in severe gas exchange and lung compliance abnormalities [4]. While a regulated inflammatory response is critical to survival [5], a major predictor of poor outcome in ARDS patients is persistence of pulmonary and systemic inflammation after 1 week of lung injury [6, 7]. Failure to downregulate the production of inflammatory mediators (dysregulated HIR) is associated with maladaptive lung repair and inability to improve ACM permeability, gas exchange, and lung mechanics over time.

The lung injury score (LIS) quantifies the physiological respiratory impairment in ARDS through the use of a fourpoint score based on the levels of positive end-expiratory pressure, arterial oxygen tension: inspiratory oxygen fraction, the static lung compliance, and the degree of infiltration present on chest radiograph [8]. Patients failing to improve the LIS or its components by day 7 of ARDS (nonimprovers) have a poor outcome [9-11]. The present authors have previously reported that patients meeting predefined criteria for unresolving ARDS (LIS on day 7 of ARDS $\geqslant 2.5$ and $<1$-point reduction from day 1 of ARDS) have a mortality rate in excess of $80 \%$ (table 1) [12].

\section{Model of translational research}

Because there is no animal model to study the progression of ARDS, translational clinical research has an important

Table 1.-Definitions of resolving and unresolving acute respiratory distress syndrome (ARDS)

\begin{tabular}{lll}
\hline Findings on day 7 of ARDS & Resolving & Unresolving \\
\hline LIS from day 1 to day 7 & $\geqslant 1$ point & $<1$ point \\
of ARDS & reduction & reduction \\
Clinical definition & Improver & Nonimprover \\
Host inflammatory response & Regulated & Dysregulated \\
Progression of lung histology & Adaptive & Maladaptive \\
Observed mortality & $14 \%$ & $83 \%$
\end{tabular}

\#: Data obtained from [12]; LIS: lung injury score. 


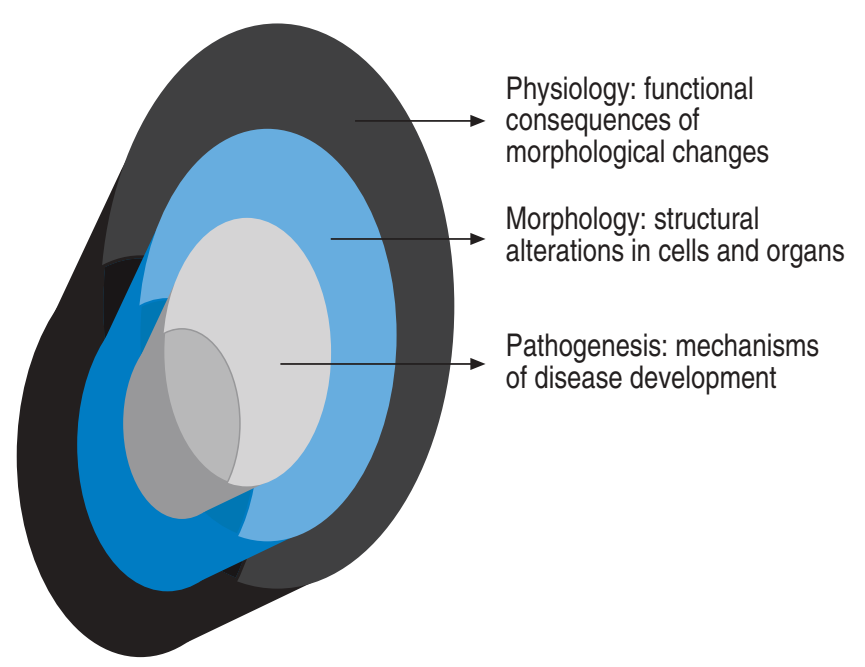

Fig. 1.-Disease elements.

role to play for advancing understanding in this field. At the University of Tennessee the current authors have followed a "holistic" level of inquiry in constructing a pathophysiological model of ARDS attempting to fit pathogenesis (biology) with morphological (pathology) and clinical (physiology) findings observed during the longitudinal course of the disease (fig. 1) [3]. Most importantly, the current authors have attempted to define the differences over time between patients with an adaptive (resolving ARDS) versus maladaptive (unresolving ARDS) reparative response, and the time span of disease reversibility (prior to reaching end-stage disease) that is potentially amenable to anti-inflammatory treatment. Patients failing to improve after 1 week of ARDS onset (unresolving ARDS) were also studied to investigate the effect of prolonged anti-inflammatory (GC) treatment. In relation to the treatment investigation, it was assumed that the closer the treatment intervention was to the core pathogenetic mechanisms of the diseases, the more likely treatment would affect all "layers" of the disease process (fig. 1). In this context, a positive or negative biological and physiological response to treatment was used to test the pathogenetic relevance (central versus peripheral) of the factor or pathway affected by treatment.

Over the last decade scientific understanding of the intermediary events that occur between the reception of a biological signal at the cell membrane, and the eventual conversion of that signal to a change in gene expression at the nuclear level (i.e. signal transduction) has grown immensely [13]. It is now recognised that two cellular signalling pathways are central to the regulation of inflammation, the stimulatory nuclear factor $-\kappa \mathrm{B}(\mathrm{NF}-\kappa \mathrm{B})$ and the inhibitory glucocorticoid receptor (GR)- $\alpha$-mediated signal transduction cascades. In unstimulated cells, both NF- $\mathrm{KB}$ and GR are predominantly sequestered in the cytoplasm.

\section{Nuclear factor-кB}

$\mathrm{NF}-\kappa \mathrm{B}$ is recognised as the central transcription factor that drives the inflammatory response to insults. NF- $\kappa \mathrm{B}$ activation is an essential step in the experimental development of neutrophilic lung inflammation [14-16]. NF- $\mathrm{BB}$ is found in essentially all cell types and is involved in activation of an exceptionally large number of target genes (over 100) [17]. $\mathrm{NF}-\kappa \mathrm{B}$ is a heterogenous collection of dimers, composed of various combinations of the NF- $\kappa \mathrm{B} / \mathrm{Rel}$ family. The $\mathrm{p} 65: \mathrm{p} 50$ heterodimer was the first form of NF- $\mathrm{B}$ to be identified and is the most abundant in most cell types [17]. NF- $\kappa \mathrm{B}$ is maintained in an inactive form by sequestration in the cytoplasm through interaction with inhibitory proteins

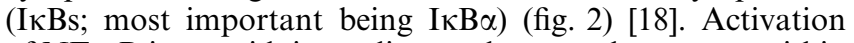
of $\mathrm{NF}-\kappa \mathrm{B}$ is a rapid, immediate early event that occurs within minutes after exposure to a relevant inducer, including innate immunity stimulating molecules (e.g. lipopolysaccharide), double-stranded deoxyribonucleic acid (DNA), physical and chemical stresses, and inflammatory cytokines (e.g. tumour necrosis factor (TNF)- $\alpha$ and interleukin (IL) $-1 \beta$ ). In response to these various stimuli, the latent $\mathrm{NF}-\kappa \mathrm{B} / \mathrm{I} \kappa \mathrm{B}$ complex is activated by phosphorylation and proteolytic degradation of $\mathrm{I} \kappa \mathrm{B}$, with exposure of the $\mathrm{NF}-\kappa \mathrm{B}$ nuclear localisation sequence [17]. Proteolytic degradation of $\mathrm{I} \kappa \mathrm{B}$ is an irreversible step in the signalling pathway that constitutes a commitment to transcriptional activation [17].

The liberated NF- $\mathrm{BB}$ then translocates into the nucleus and binds to promoter regions of target genes to initiate the transcription of multiple cytokines including TNF- $\alpha$, and the interleukins IL-1 $\beta$, IL-2, IL-6, chemokines such as IL-8, cell adhesion molecules (e.g. intercellular adhesion molecule-1, E-selectin), interferon, receptors involved in immune recognition such as members of the major histocompatibility complex, proteins involved in antigen presentation, receptors required for neutrophil adhesion and migration, and inflammation-associated enzymes (cyclooxygenase, phospholipase A2 $\left(\mathrm{PLA}_{2}\right)$, inducible nitric oxide synthase) $[18,19]$. Products of the genes that are stimulated by $N F-\kappa B$ activate this transcription factor. Thus, TNF- $\alpha$ and IL- $1 \beta$ both activate and are activated by $\mathrm{NF}-\kappa \mathrm{B}$, by forming a positive regulatory loop that amplifies and perpetuates inflammation [20]. NF- $\kappa \mathrm{B}$ also operates in conjunction with other transcription factors, including activator protein-1 (AP-1) [21].

\section{Glucocorticoid receptor}

Peripherally generated TNF- $\alpha$, IL-1 $\beta$, and IL-6 activate the hypothalamic-pituitary-adrenal (HPA) axis independently at some or all of its levels [22, 23]. The HPA axis responds in a graded manner to greater intensities of stress with increased production of adrenocorticotropic hormone (ACTH) and GCs. Due to their hormonal and lipophilic nature, GCs pass freely through the cell membrane. GCs exert most of their effects by activating ubiquitously distributed $(2,000$ to 30,000 per cell) cytoplasmic heat shock protein-complexed GR with formation of GC-GR complexes [24]. It is now appreciated that the GC-GR complexes modulate transcription in a hormone-dependent manner by binding as a dimer to glucocorticoid-responsive elements (GREs) located in the promoter regions of $\mathrm{GC}$ responsive genes and by interfering with the activity of other transcription factors such as NF- $\kappa \mathrm{B}$ on genes regulated by these factors [25]. As a dimer and/or a monomer, GR-mediated transcriptional interference is achieved by five important mechanisms (fig. 2): 1) physically interacting with the p65 subunit and formation of an inactive (GR-NF-кB) complex [24]; 2) by inducing the transcription of the inhibitory protein $\mathrm{I} \kappa \mathrm{B} \alpha$ gene $[24,26$, 27]; 3) by blocking degradation of $\mathrm{I} \kappa \mathrm{B} \alpha$ via enhanced synthesis of IL-10 [28-30]; 4) by impairing TNF- $\alpha$-induced degradation of $I \kappa B \alpha[31,32]$ and 5) by competing for limited amounts of GR co-activators such as CREB-binding protein and steroid receptor coactivator-1 [33]. In addition to the transcriptional modulation described above, GCs also influence the processing of messenger ribonucleic acid (mRNA) and translation of proteins probably through transactivation 


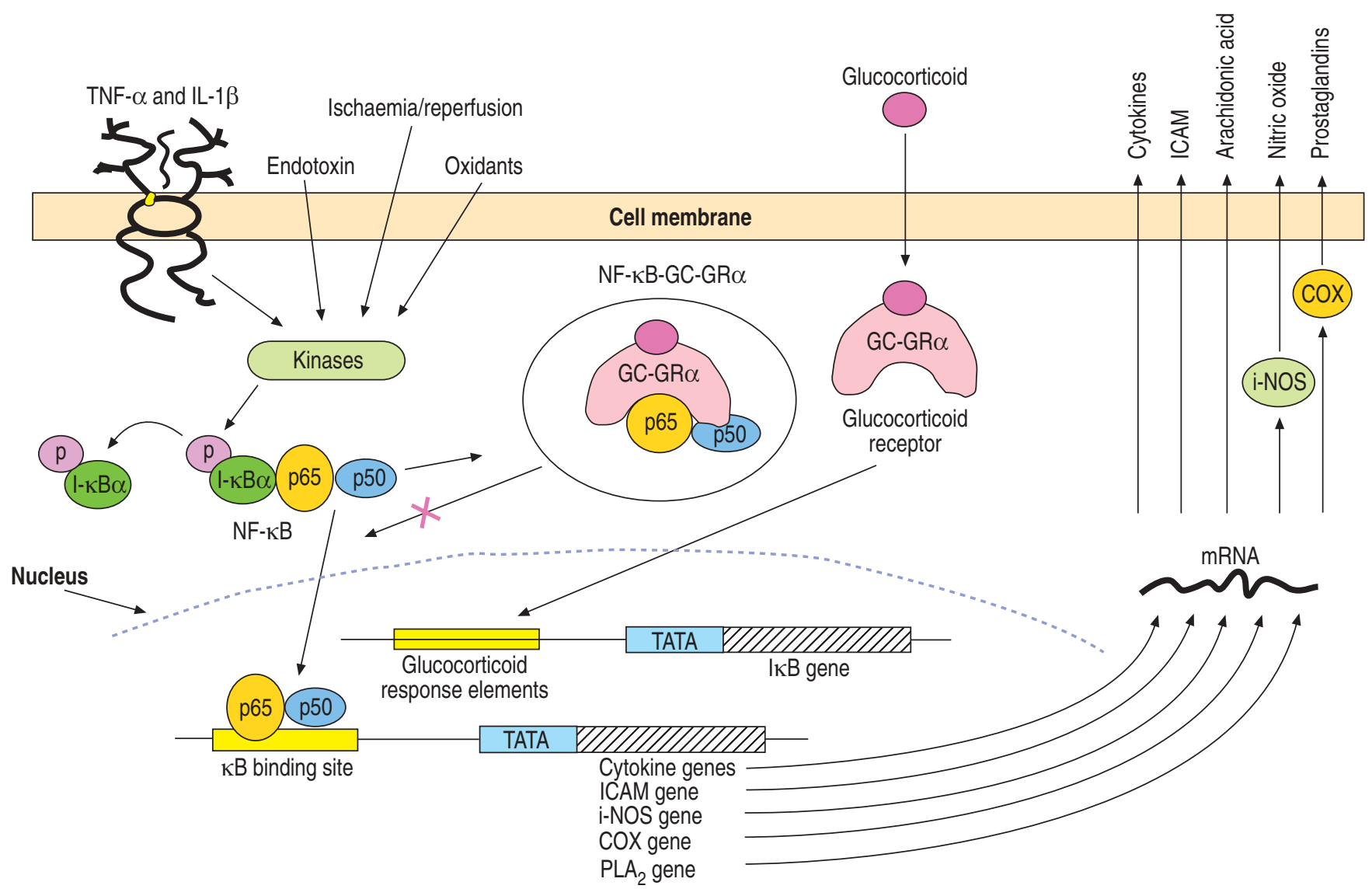

Fig. 2. - Interaction between nuclear factor (NF)- $\mathrm{kB}$ and the activated glucocorticoid receptor (GR). When cells are stimulated by inflammatory signals, specific kinases phosphorylate the inhibitory protein I KB and cause its rapid degradation. The activated form of NF- $\kappa$ B then moves to the nucleus initiating the transcription of the messenger ribonucleic acid (mRNA) of inflammatory cytokines, chemokines, cell adhesion molecules (e.g. intercellular adhesion molecule (ICAM)), and inflammation-associated enzymes (cyclooxygenase (COX), phospholipase $\mathrm{A}_{2}$ $\left(\mathrm{PLA}_{2}\right)$, inducible nitric oxide synthase (iNOS)). Cortisol or exogenous glucocorticoids (GCs) freely cross into the cytoplasm and bind to their specific GC receptors $(\mathrm{GR} \alpha)$ to form the activated receptor $(\mathrm{GC}-\mathrm{GR} \alpha)$. GC-GR $\alpha$ complexes may influence NF- $\mathrm{kB}$ activity in 5 major ways: 1$)$ physically interacting with the p65 subunit with formation of an inactive (GC-GR $\alpha / \mathrm{NF}-\kappa \mathrm{B})$ complex; 2) inducing the synthesis of the inhibitory

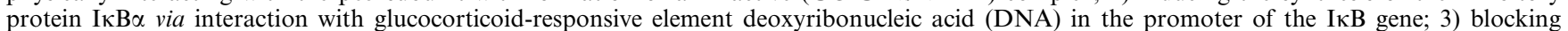

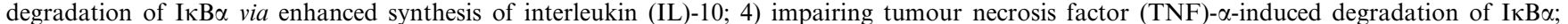
and 5) competing for limited amounts of GR co-activators such as CREB-binding protein and steroid receptor coactivator-1. GC-GR $\alpha$ may also decrease the stability of mRNA of several pro-inflammatory cytokines and other molecules. Products of the genes that are stimulated by NF- $\mathrm{kB}$ activate this transcription factor. Thus, TNF- $\alpha$ and IL- $1 \beta$ both activate and are activated by NF- $\mathrm{KB}$, by forming a positive regulatory loop that amplifies and perpetuates inflammation.

or transrepression of genes that regulate mRNA stability and translation [34].

\section{Inflammation-associated glucocorticoid inadequacy/resistance}

GCs as end-effectors of the hypothalamic-pituitary-adrenal axis are the most important natural inhibitors of inflammation [35]. However, endogenous GCs are not always effective in suppressing life-threatening systemic inflammation, even though the degree of cortisolemia frequently correlates with severity of illness and mortality rate [36-39]. Unquestionably, the elevation of GC secretion in nonsurvivors is inadequate to meet the needs of the concurrent inflammatory response and its adverse systemic effects. Failure to suppress inflammation could be due to tissue resistance to GCs, inadequacy of the level and duration of endogenous GC elevation to suppress an HIR gone awry, or both [40].

The concept of acquired GC resistance was first introduced by KASS and FINLAND [41] in 1957. These investigators suggested that increased blood cortisol levels in patients with sepsis may reflect a block to steroidal activity or transport, as a consequence of the infection. In this situation, a small increase in blood levels with a low (equal or less than physiological) dose of exogenous GCs was believed to be sufficient for facilitating the passage of steroids into host cells [41]. GR-mediated resistance was originally described as a primary inherited familial syndrome $[42,43]$ and was recently recognised as an "acquired" condition. Among others, acquired immune tissue-specific GR resistance has been described in patients with asthma [44-47], acquired immunodeficiency syndrome (AIDS) [48] and severe sepsis [49].

Recent in vitro studies have shown that cytokines may induce resistance to GCs by reducing GR binding affinity to cortisol and/or GREs [50-52]. Such abnormalities of GR function were demonstrated in T-cells incubated with a combination of IL-2 and IL-4 [51]. IL-1, IL-6, and interferon (IFN)- $\gamma$ [50] or IL-13 [52]. GC resistance was induced in a cytokine concentration-dependent fashion and was reversed by the removal of cytokines [51]. GR-mediated resistance in the presence of systemic inflammation was also studied in experimental models of sepsis and sepsis-induced ARDS [49, $53,54]$. In a sheep model of sepsis-induced ARDS, maximal 
binding capacity of GR decreased continuously after endotoxin infusion, while there was a marked elevation of cortisol levels [53]. The reduced GR binding correlated negatively $(\mathrm{r}=-0.87, \mathrm{p}<0.01)$ with $\mathrm{PLA}_{2}$ activity, a gene that is stimulated by $N F-\kappa B$. In a rat model of septic shock, GR blockade by mifepristone (RU 486) exacerbated the physiological and pathological changes induced by endotoxemia [54]. PLA 2 activity in rats with $80 \%$ GR blockade was more marked than in those with $50 \%$ GR blockade [54]. Monocytes of patients with sepsis developed near total GC resistance in vitro, when cytokines, especially IL-2, were added [49].

Several inflammatory cytokines, including TNF- $\alpha$, IL- $1 \beta$, and IL-6 activate NF- $\kappa \mathrm{B}$ [55]. It has been proposed that when cytokine-activated $\mathrm{NF}-\kappa \mathrm{B}$ forms protein-protein complexes with activated GR, the availability and activity of effective GR molecules are reduced [24, 47]. This functional reduction in GR availability is associated with decreased GR-GRE DNA binding and GC-mediated anti-inflammatory activity [24, 47].

\section{Longitudinal studies of biomarkers of host inflammatory response in acute respiratory distress syndrome}

The current authors previously reported data to support a single "hit" model for ARDS progression, where degree and duration of the HIR determined the adaptive versus maladaptive evolution of the reparative process and final outcome. In a series of studies [56-59] the current authors have shown that patients with ARDS failing to improve in the first week of mechanical ventilation (unresolving ARDS) had biological and morphological evidence of intense and protracted pulmonary and systemic inflammatory and neofibrogenetic activity. Over time, patients with unresolving ARDS had persistent and exaggerated elevation in plasma and bronchoalveolar lavage (BAL) levels of TNF- $\alpha$, IL-1 $\beta$, IL-6, IL-8, [56-59] soluble intercellular adhesion molecule-1 (sICAM-1) [58] and procollagen aminoterminal propeptide type I (PINP) and type III (PIIINP) [60]. During the first week of ARDS, pro-inflammatory cytokine levels declined in all survivors, while levels remained persistently elevated in all nonsurvivors. Recent data from the present authors' group indicate that cytokine levels reflected true biological activity [61]. Furthermore, histological findings of open lung biopsies obtained in patients with unresolving ARDS (day $15 \pm 7$ of mechanical ventilation) provided morphological evidence of persistent activation of the HIR. Histological findings in previously spared pulmonary lobules included new injury to the endothelial and epithelial surfaces with associated intravascular coagulation and extravascular fibrin deposition $[6,7]$. Histological findings in previously involved pulmonary lobules included progressive fibroproliferative obliteration with transformation of the initially fibrinous exudate into myxoid connective tissue matrix and eventually into dense acellular fibrous tissue $[6,7]$. Histological differences between survivors and nonsurvivors placed advanced pulmonary fibrosis with acellular fibrosis and loss of alveolar architecture at the upper boundary of disease reversibility [6].

\section{Glucocorticoid treatment of unresolving acute respiratory distress syndrome}

Large randomised studies have previously shown that a short course $(\leqslant 24 \mathrm{~h})$ of high-dose methylprednisolone (MP) in early ARDS is ineffective [10, 62-64]. Table 2 shows the differences between the older trials in early ARDS and the newer one in unresolving ARDS. The reference of MEDURI [65] provides an historical review of GC treatment in sepsis and ARDS in relation to the evolving pathophysiological understanding of systemic inflammation. Because the half-life of MP is $\sim 180 \mathrm{~min}$, a sustained pharmacological effect in life threatening protracted lung inflammation (i.e. status asthmaticus, Pneumocystis carinii pneumonia, etc.) can be achieved only with prolonged administration aimed at disease resolution. In a rat model of butylated hydroxytoluene-induced acute lung injury, GC administration was shown to be effective in decreasing lung collagen and oedema formation as long as treatment was prolonged; while withdrawal rapidly negated the positive effects of therapy [66-68]. Two clinical studies demonstrated that premature discontinuation of prolonged GC administration in unresolving ARDS was associated with physiological deterioration that resolved with re-institution of treatment $[69,70]$. Moreover, studies suggest that premature discontinuation of GC therapy may not only lead to loss of the early treatment benefits, but may in fact be harmful. Indeed, in another study the cytokine response to lipopolysaccharide challenge in humans was significantly enhanced by a prior (12-144 h) short course of GCs [71]. This observation may explain the differences in infectionrelated mortality between studies utilising a short course (24 h) [63] versus a prolonged course of methylprednisolone treatment $[12,72]$.

Similar to the original reports from ASHBAUGH and MAIER [69] and HOOPER and KEARL [70] the current authors investigated the use of prolonged MP administration in patients with unresolving ARDS. The current authors and others have reported significant improvement in lung function during prolonged MP administration in medical [6, 70, 73, 74] and surgical $[69,75]$ patients with unresolving ARDS and have found that survival correlated with improvement in lung function. The current authors' studies [6, 73] defined improvement in lung function as a reduction in LIS [8] of at least one point after 10 to 14 days of MP treatment. In phase II trials involving 34 patients, mortalities of $17 \%$ were reported in 29 patients who improved lung function (responders) and 100\% in 5 nonresponders [6, 73]. Additional findings of phase II trials are shown in tables 3 and 4 .

Most recently the present authors completed a prospective, randomised, double-blind, placebo-controlled trial designed to evaluate the efficacy of prolonged MP treatment (MPT) in patients with unresolving ARDS [72]. Methylprednisolone or

Table 2. - Comparison of old and new trials investigating methylprednisolone use in acute respiratory distress syndrome (ARDS)

1980s trials

$<2$ days

$120 \mathrm{mg} \cdot \mathrm{kg}^{-1} \cdot \mathrm{day}^{-1}$

1 day

Massive, short-lived

Reversibility lost early

Massive, short-course 1990s trials
7-14 days (unresolved)
$2 \mathrm{mg} \cdot \mathrm{kg}^{-1} \cdot \mathrm{day}^{-1}$
Average 30 days
Prolonged, initial intensity affects duration
Reversibility lost with end-stage fibrosis
Lower dose, prolonged until resolution

HIR: host inflammatory response; GCT: glucocorticoid treatment. 
Table 3. - Phase II studies evaluating methylprednisolone in unresolving acute respiratory distress syndrome (ARDS). Findings at initiation of methylprednisolone treatment

\section{General findings}

Fever was frequently present in the absence of infection $[6,76]$

Plasma and BAL inflammatory cytokine ${ }^{\#}$ levels

Were similar levels to control nonsurvivors [73]

Had no spontaneous reduction over time [73]

Lack of significant bacterial growth in BAL correlated with histological absence of pneumonia [6, 76]

${ }^{67}$ Gallium scintigraphy with marked and diffuse pulmonary uptake in the absence of pneumonia [77]

\section{Comparison between responders and nonresponders}

Responders had:

Histological evidence of preserved alveolar architecture and myxoid cellular fibroproliferation [6]

Improvement in lung injury score was slower in those with

Higher plasma IL-6 levels $[73]^{+}$

Histological evidence of more advanced fibroproliferation [6]

Nonresponders had:

Histological evidence of acellular fibrosis, arteriolar subintimal fibroproliferation, and loss of alveolar architecture [6]

Higher incidence of liver failure $(50 \%$ versus $5 \%$; $=0.0035)$ [6]

Higher plasma IL-6 levels on days $1-3$ of ARDS [73] $]^{+}$

Physiological evidence of accelerated fibroproliferation [6]

\#: Inflammatory cytokines included tumour necrosis factor- $\alpha$, interleukin (IL)-1 $\beta$, IL-6, and IL-8; ๆ : histological findings from lung specimens obtained by open lung biopsy in 13 patients with unresolving ARDS on mechanical ventilation for $15 \pm 7$ days, and prior to initiating prolonged methylprednisolone treatment; ${ }^{+}:$Plasma IL-6 levels on days 1-3 of ARDS: nonresponders versus responders: $1903 \pm 302 \mathrm{pg} \cdot \mathrm{mL}^{-1}$ versus $1050 \pm 191 \mathrm{pg} \cdot \mathrm{mL}^{-1} \quad(\mathrm{p}=0.004)$; at initiation of methylprednisolone therapy: delayed versus rapid responders: $1011 \pm 44 \mathrm{pg} \cdot \mathrm{mL}^{-1}$ versus $526 \pm 57 \mathrm{pg} \cdot \mathrm{mL}^{-1}(\mathrm{p}=0.03)$; BAL: bronchoalveolar lavage.

Table 4. - Phase II studies evaluating methylprednisolone in unresolving acute respiratory distress syndrome (ARDS). Findings during methylprednisolone treatment

\section{General findings}

Infections frequently developed in the absence of fever

Warning signs included $\geqslant 10 \%$ increase in immature neutrophils

$\geqslant 30 \%$ increase in minute ventilation

Ventilator-associated pneumonia was the most common infection

Surveillance bronchoscopy with bilateral BAL was useful for detecting pneumonia

Accurately identified and treated infections did not increase plasma and BAL cytokine levels above pre-infection levels.

Premature discontinuation of treatment was associated with deterioration in lung function $[69,70]$

Comparison between responders versus nonresponders

Responders had a:

Reduction in plasma and BAL inflammatory cytokine levels ${ }^{\#}$

Significant by day 5 of treatment, and

Parallel to improvements in lung injury score and indices of $\mathrm{ACM}^{\bullet}$ permeability

$>1$-point reduction in lung injury score by day 10 of treatment

$17 \%$ mortality

Nonresponders had

No reduction in plasma and BAL inflammatory cytokine levels

No improvements in lung injury score and $\mathrm{ACM}^{\circ}$ permeability

$100 \%$ mortality

\#: Inflammatory cytokines included tumour necrosis factor- $\alpha$, interleukin (IL)-1B, IL-6, and IL-8; ${ }^{\text {: }}$ Alveolo-capillary membrane (ACM) permeability was assessed by measuring bronchoalveolar lavage (BAL) albumin concentration over time.

placebo was given daily as intravenous push every $6 \mathrm{~h}$ (onefourth of the daily dose) and changed to a single per os dose when oral intake was restored. The MP dosage regimen is shown in table 5 . If the patient was extubated prior to day 14 , treatment was advanced to day 15 of drug therapy and tapered according to schedule [72]. The protocol contained: 1) a provision for blindly crossing over patients who did not improve LIS by at least 1 point after 10 days of treatment or earlier crossover in patients with life-threatening deterioration in gas exchange and; 2) procedures for infection surveillance, including weekly bronchoscopy with bilateral BAL [72]. Because MP blunts the febrile response to an infection, this

Table 5. - Methylprednisolone treatment in unresolving acute respiratory distress syndrome

\begin{tabular}{llll}
\hline Loading dose & $2 \mathrm{mg} \cdot \mathrm{kg}^{-1} \mathrm{IV}$ bolus followed by: & \\
\hline Days 1-14 & $2 \mathrm{mg} \cdot \mathrm{kg}^{-1} \cdot \mathrm{day}^{-1}$ as & $0.5 \mathrm{mg} \cdot \mathrm{kg}^{-1}$ & IV push every $6 \mathrm{~h}$ \\
Days 15-21 & $1 \mathrm{mg} \cdot \mathrm{kg}^{-1} \cdot \mathrm{day}^{-1}$ as & $0.25 \mathrm{mg} \cdot \mathrm{kg}^{-1}$ & IV push every 6 h \\
Days 22-28 & $0.5 \mathrm{mg} \cdot \mathrm{kg}^{-1} \cdot \mathrm{day}^{-1}$ as & $0.125 \mathrm{mg} \cdot \mathrm{kg}^{-1}$ & $\mathrm{IV} \mathrm{push} \mathrm{every} 6 \mathrm{~h}$ \\
\hline
\end{tabular}

\#: From days 29-32, methylprednisolone was given in a single per os dose of $0.25 \mathrm{mg} \cdot \mathrm{kg}^{-1} \cdot \mathrm{day}^{-1}$ for 2 days and $0.125 \mathrm{mg} \cdot \mathrm{kg}^{-1} \cdot \mathrm{day}{ }^{-1}$ for $2 \mathrm{days}$. IV: intravenous. 
latter intervention was essential for minimising the random variation generated by the potential morbidity and mortality of untreated nosocomial infections. The study was designed as a sequential phase III clinical trial and projected to recruit 100 patients. The decision to end the trial was made when the test statistic exceeded the upper boundary of the triangular test of Whitehead, and the null hypothesis was rejected at a significance $<0.05$ and a power $>0.95$.

The two groups were similar at study entry. After ten days, all patients in the MPT group improved $(\geqslant 1$ point reduction in LIS) versus 2 of $8(25 \%)$ in the placebo group. Intensive care unit and hospital-associated mortality were significantly reduced: $0 \%$ versus $62 \%(\mathrm{p}=0.002)$ and $12 \%$ versus $62 \%$ $(\mathrm{p}=0.03)$, respectively. The small number of patients may have biased the estimate of the treatment effect. The rate of complications between the two groups was similar. During MP treatment, pneumonia frequently developed in patients without fever $(44 \%)$. Therefore, infection surveillance, including weekly bilateral bronchoscopic BAL, was useful for early detection of pneumonia and other serious infections. None of the recognised and appropriately treated infections developing during MP therapy affected resolution of ARDS or clinical outcome. Since the study was completed, the present authors routinely use prolonged MPT in patients with unresolving ARDS with a physiological improvement observed in $60-80 \%$ of patients.

The therapeutic anti-inflammatory and anti-fibrotic efficacy of prolonged MPT was assessed with serial measurements of HIR biomarkers. MPT was associated with a rapid and sustained reduction in mean plasma and BAL TNF- $\alpha$, IL-1 $\beta$, IL-6, IL-8, sICAM-1, IL-1 receptor antagonist (IL-1ra), soluble TNF receptor 1 and 2 (sTNFR1 and sTNFR2), PINP and PIIINP, and with increases in IL-10 and in antiinflammatory-to-pro-inflammatory cytokine ratios (IL-1ra/ IL-1 $\beta$, IL-10/TNF- $\alpha$, IL-10/IL-1 $\beta$ ) [59, 60, 78]. Placebo administration was not associated with reductions in HIR biomarkers. The current authors believe that failure of older trials investigating massive doses of MP in early ARDS (table 2) was attributable to the short duration of administration and not to timing of administration.

\section{Evidence of inflammation-associated glucocorticoid inadequacy/resistance in unresolving acute respiratory distress syndrome}

Using an ex vivo model of systemic inflammation in ARDS the current authors investigated intracellular upstream and downstream events associated with DNA-binding of NF- $\kappa$ B and GR $\alpha$ in the peripheral blood leukocytes (PBLs) (naive cells) obtained from a healthy volunteer (laboratory work conducted by F. Stentz, Dept of Medicine, Pulmonary and Critical Care Division, The University of Tennessee Health Science Center, Memphis, Tennessee, USA) [79]. PBLs were incubated for $3 \mathrm{~h}$ with 98 plasma samples obtained longitudinally from 17 patients with ARDS before and after randomisation to either placebo $(n=6)$ or MP $(n=11)$. The cells were processed for fractionation into cytosolic and nuclear components, ribonucleic acid (RNA) extraction, and intracellular labelling. The primary objectives of these studies were to quantify the relationships among circulating levels of inflammatory cytokines TNF- $\alpha$ and IL-1 $\beta$ and HPA-axis hormones (ACTH and cortisol), and intracellular activities mediated by $\mathrm{NF}-\kappa \mathrm{B}(\mathrm{NF}-\kappa \mathrm{B} \kappa \mathrm{b}$-binding and transcription of TNF- $\alpha$ and IL-1 $\beta)$ and GR $\alpha(G R \alpha$ binding to NF- $\kappa B, G R \alpha$ binding to GRE DNA, stimulation of inhibitory protein $\mathrm{I} \kappa \mathrm{B} \alpha$, and stimulation of IL-10 transcription).

In the observation period prior to randomisation, the biological and physiological characteristics of the MP and placebo groups were similar. Patients had persistent elevations in plasma levels of inflammatory (TNF- $\alpha$, IL-1 $\beta$, and IL-6) cytokines and HPA-axis (ACTH and cortisol) hormones and similar severity of organ dysfunction scores. In PBLs exposed to patients' plasma GR $\alpha$-mediated activities

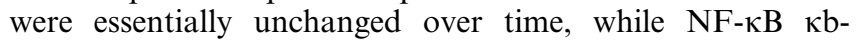
binding and transcription of TNF- $\alpha$ and IL-1 $\beta$ increased over time. The current authors' hypothesised that inadequate secretion of cortisol and/or immune tissue resistance to endogenous GCs might explain the observed failure of activated GR to suppress inflammation (progressive increase in $\mathrm{NF}-\kappa \mathrm{B}$-mediated activities) in the presence of persistently elevated ACTH and cortisol levels.

Patients treated with MP had rapid, progressive and sustained reductions in plasma TNF- $\alpha$, IL-1 $\beta$, IL- 6 , ACTH and cortisol levels over time. These were associated with parallel improvements in pulmonary and extrapulmonary organ dysfunction scores (previously reported in reference [72]). Normal PBL exposed to plasma samples collected during MP versus placebo treatment also exhibited rapid, progressive significant increases in GR $\alpha$-mediated activities (GR $\alpha$ binding to $\mathrm{NF}-\kappa \mathrm{B}, \mathrm{GR} \alpha$ binding to GRE DNA, stimulation of inhibitory protein $\mathrm{I} \kappa \mathrm{B} \alpha$, and stimulation of IL10 transcription), and significant reductions in NF- $\kappa \mathrm{B} \kappa \mathrm{b}-$ binding and transcription of TNF- $\alpha$ and IL-1 $\beta$. With MPT, the intracellular relations between the $N F-\kappa B$ and $G R \alpha$ signalling pathways changed from an initial NF- $\kappa \mathrm{B}-$ driven and GR-resistant state to a GR-driven and GR-sensitive one.

The current authors interpret the responses observed during methylprednisolone treatment to support the concept of inflammation-dependent acquired glucocorticoid resistance in patients with unresolving acute respiratory distress syndrome. The findings also underscore the central role played by activated glucocorticoid receptor- $\alpha$ in regulating inflammation and provide strong mechanistic evidence for the efficacy of prolonged methylprednisolone treatment in unresolving acute respiratory distress syndrome. A controlled trial is in progress to evaluate the effect of prolonged methylprednisolone treatment initiated within $72 \mathrm{~h}$ of acute respiratory distress syndrome development.

\section{References}

1. Katzenstein AL, Bloor CM, Leibow AA. Diffuse alveolar damage - the role of oxygen, shock, and related factors. A review. Am J Pathol 1976; 85: 209-228.

2. Meduri GU. The role of the host defence response in the progression and outcome of ARDS: pathophysiological correlations and response to glucocorticoid treatment. Eur Respir J 1996; 9: 2650-2670.

3. Cotran RS, Kumar V, Robbins SL. Cellular injury and cellular death. In: Cotran RS, Kumar V, Robbins SL, eds. Pathologic basis of disease. 5th Edn. Philadelphia, W.B. Saunders, 1994; pp. 1-34.

4. Steinberg KP, Hudson LD. Acute lung injury and acute respiratory distress syndrome. The clinical syndrome. Clin Chest Med 2000; 21: 401-417.

5. McKay LI, Cidlowski JA. Molecular control of immune/ inflammatory responses: interactions between nuclear factor-kappa B and steroid receptor-signaling pathways. Endocr Rev 1999; 20: 435-459.

6. Meduri GU, Chinn AJ, Leeper KV, et al. Corticosteroid rescue treatment of progressive fibroproliferation in late ARDS. Patterns of response and predictors of outcome. Chest 1994; 105: 1516-1527.

7. Meduri GU, Eltorky M, Winer-Muram HT. The fibroproliferative phase of late adult respiratory distress syndrome. Semin Respir Infect 1995; 10: 154-175. 
8. Murray JF, Matthay MA, Luce JM, Flick MR. An expanded definition of the adult respiratory distress syndrome. Am Rev Respir Dis 1988; 138: 720-723.

9. Bone RC, Maunder R, Slotman G, et al. An early test of survival in patients with the adult respiratory distress syndrome. The $\mathrm{PaO}_{2} / \mathrm{FIO}_{2}$ ratio and its differential response to conventional therapy. Prostaglandin E1 Study Group. Chest 1989; 96: 849-851.

10. Bernard GR, Luce JM, Sprung CL, et al. High-dose corticosteroids in patients with the adult respiratory distress syndrome. N Engl J Med 1987; 317: 1565-1570.

11. Meduri GU. Host defense response and outcome in ARDS. Chest 1997; 112: 1154-1158.

12. Headley AS, Tolley E, Meduri GU. Infections and the inflammatory response in acute respiratory distress syndrome. Chest 1997; 111: 1306-1321.

13. Shanley TP, Wong HR. Signal transduction pathways in acute lung injury: NF-кB and AP-1. In: Wong HR, Shanley TP, eds. Molecular Biology of Acute Lung Injury, Molecular and Cellular Biology of Critical Care Medicine. Boston, Kluwer, 2001; pp. 1-16.

14. Ross SD, Kron IL, Gangemi JJ, et al. Attenuation of lung reperfusion injury after transplantation using an inhibitor of nuclear factor-kappaB. Am J Physiol Lung Cell Mol Physiol 2000; 279: L528-536.

15. Lentsch AB, Czermak BJ, Bless NM, Van Rooijen N, Ward PA. Essential role of alveolar macrophages in intrapulmonary activation of NF-kappaB. Am J Respir Cell Mol Biol 1999; 20: 692-698.

16. Christman JW, Sadikot RT, Blackwell TS. The role of nuclear factor-kappa B in pulmonary diseases. Chest 2000; 117: 1482-1487.

17. Karin M, Ben-Neriah Y. Phosphorylation meets ubiquitination: the control of NF-[kappa]B activity. Annu Rev Immunol 2000; 18: 621-663.

18. Baeuerle PA, Baltimore D. NF-kappa B: ten years after. Cell 1996; 87: 13-20.

19. Yamamoto Y, Gaynor RB. Therapeutic potential of inhibition of the NF-kappaB pathway in the treatment of inflammation and cancer. J Clin Invest 2001; 107: 135-142.

20. Barnes PJ, Karin M. Nuclear factor-kappa B: a pivotal transcription factor in chronic inflammatory diseases. $N$ Engl J Med 1997; 336: 1066-1071.

21. Stein B, Baldwin AS Jr, Ballard DW, Greene WC, Angel P, Herrlich P. Cross-coupling of the NF-kappa B p65 and Fos/ Jun transcription factors produces potentiated biological function. EMBO J 1993; 12: 3879-3891.

22. Perlstein RS, Whitnall MH, Abrams JS, Mougey EH, Neta R. Synergistic roles of interleukin-6, interleukin-1, and tumor necrosis factor in the adrenocorticotropin response to bacterial lipopolysaccharide in vivo. Endocrinology 1993; 132: 946-952.

23. Hermus AR, Sweep CG. Cytokines and the hypothalamicpituitary-adrenal axis. J Steroid Biochem Mol Biol 1990; 37: 867-871.

24. Bamberger CM, Schulte HM, Chrousos GP. Molecular determinants of glucocorticoid receptor function and tissue sensitivity to glucocorticoids. Endocr Rev 1996; 17: 245-261.

25. Didonato JA, Saatcioglu F, Karin M. Molecular mechanisms of immunosuppression and anti-inflammatory activities by glucocorticoids. Am J Respir Crit Care Med 1996; 154: S11-15.

26. Scheinman RI, Cogswell PC, Lofquist AK, Baldwin AS Jr. Role of transcriptional activation of I kappa B alpha in mediation of immunosuppression by glucocorticoids. Science 1995; 270: 283-286.

27. Wissink S, van Heerde EC, vand der Burg B, van der Saag PT. A dual mechanism mediates repression of NF-kappa B activity by glucocorticoids. Mol Endocrinol 1998; 12: 355-363.

28. Wang $\mathrm{P}, \mathrm{Wu} \mathrm{P}$, Siegel $\mathrm{MI}$, Egan RW, Billah MM. Interleukin (IL)-10 inhibits nuclear factor kappa B (NF kappa B) activation in human monocytes. IL-10 and IL-4 suppress cytokine synthesis by different mechanisms. $J$ Biol Chem 1995; 270: 9558-9563.

29. Lentsch AB, Shanley TP, Sarma V, Ward PA. In vivo suppression of NF-kappa B and preservation of I kappa B alpha by interleukin-10 and interleukin-13. J Clin Invest 1997; 100: 2443-2448.

30. Shames BD, Selzman CH, Meldrum DR, et al. Interleukin10 stabilizes inhibitory kappaB-alpha in human monocytes. Shock 1998; 10: 389-394.

31. Hoffman SL, Punjabi NH, Kumala S, et al. Reduction of mortality in chloramphenicol-treated severe typhoid fever by high-dose dexamethasone. N Engl J Med 1984; 310: 82-88.

32. Poppers DM, Schwenger P, Vilcek J. Persistent tumor necrosis factor signaling in normal human fibroblasts prevents the complete resynthesis of I kappa B-alpha. $J$ Biol Chem 2000; 275: 29587-29593.

33. Sheppard KA, Phelps KM, Williams AJ, et al. Nuclear integration of glucocorticoid receptor and nuclear factorkappaB signaling by CRE-binding protein and steroid receptor coactivator-1. J Biol Chem 1998; 273: 29291-29294.

34. Bamberger CM, Bamberger AM, de Castro M, Chrousos GP. Glucocorticoid receptor beta, a potential endogenous inhibitor of glucocorticoid action in humans. J Clin Invest 1995; 95: 2435-2441.

35. Chrousos GP. The hypothalamic-pituitary-adrenal axis and immune-mediated inflammation. N Engl J Med 1995; 332: 1351-1362.

36. Melby JC, Spink WW. Comparative studies on adrenalcortical function and cortisol metabolism in healthy adults and in patients with shock due to infection. Journal of Clinical Investigation 1958; 37: 1791-1798.

37. Reincke M, Allolio B, Wurth G, Winkelmann W. The hypothalamic-pituitary-adrenal axis in critical illness: response to dexamethasone and corticotropin-releasing hormone. J Clin Endocrinol Metab 1993; 77: 151-156.

38. Briegel J, Forst H, Hellinger H, Haller M. Contribution of cortisol deficiency to septic shock. Lancet 1991; 338: 507-508.

39. Annane D, Sebille V, Troche G, Raphael JC, Gajdos P, Bellissant E. A 3-level prognostic classification in septic shock based on cortisol levels and cortisol response to corticotropin. JAMA 2000; 283: 1038-1045.

40. Meduri GU, Chrousos GP. Duration of glucocorticoid treatment and outcome in sepsis: is the right drug used the wrong way? Chest 1998; 114: 355-360.

41. Kass EH, Finland M. Adrenocortical hormones and the management of infection. Ann Rev Med 1957; 8: 1-18.

42. Chrousos GP, Detera-Wadleigh SD, Karl M. Syndromes of glucocorticoid resistance. Annals of Internal Medicine 1993; 119: 1113-1124.

43. Lamberts SW, Koper JW, Biemond P, den Holder FH, de Jong FH. Cortisol receptor resistance: the variability of its clinical presentation and response to treatment. J Clin Endocrinol Metab 1992; 74: 313-321.

44. Lane SJ, Lee TH. Glucocorticoid receptor characteristics in monocytes of patients with corticosteroid-resistant bronchial asthma. Am Rev Respir Dis 1991; 143: 1020-1024.

45. Sher ER, Leung DY, Surs W, et al. Steroid-resistant asthma. Cellular mechanisms contributing to inadequate response to glucocorticoid therapy. J Clin Invest 1994; 93: 33-39.

46. Adcock IM, Lane SJ, Brown CR, Peters MJ, Lee TH, Barnes PJ. Differences in binding of glucocorticoid receptor to DNA in steroid-resistant asthma. J Immunol 1995; 154: 3500-3505.

47. Barnes PJ, Greening AP, Crompton GK. Glucocorticoid resistance in asthma. Am J Respir Crit Care Med 1995; 152: S125-140.

48. Norbiato G, Bevilacqua M, Vago T, et al. Cortisol resistance in acquired immunodeficiency syndrome. J Clin Endocrinol Metab 1992; 74: 608-613.

49. Molijn GJ, Spek JJ, van Uffelen JC, et al. Differential 
adaptation of glucocorticoid sensitivity of peripheral blood mononuclear leukocytes in patients with sepsis or septic shock. J Clin Endocrinol Metab 1995; 80: 1799-1803.

50. Almawi WY, Lipman ML, Stevens AC, Zanker B, Hadro ET, Strom TB. Abrogation of glucocorticoidmediated inhibition of $\mathrm{T}$ cell proliferation by the synergistic action of IL-1, IL-6, and IFN-gamma. J Immunol 1991; 146: 3523-3527.

51. Kam JC, Szefler SJ, Surs W, Sher ER, Leung DY. Combination IL-2 and IL-4 reduces glucocorticoid receptorbinding affinity and $\mathrm{T}$ cell response to glucocorticoids. J Immunol 1993; 151: 3460-3466.

52. Spahn JD, Szefler SJ, Surs W, Doherty DE, Nimmagadda SR, Leung DY. A novel action of IL-13: induction of diminished monocyte glucocorticoid receptor-binding affinity. J Immunol 1996; 157: 2654-2659.

53. Liu LY, Sun B, Tian Y, Lu BZ, Wang J. Changes of pulmonary glucocorticoid receptor and phospholipase $\mathrm{A}_{2}$ in sheep with acute lung injury after high dose endotoxin infusion. Am Rev Respir Dis 1993; 148: 878-881.

54. Fan J, Gong XQ, Wu J, Zhang YF, Xu RB. Effect of glucocorticoid receptor (GR) blockade on endotoxemia in rats. Circ Shock 1994; 42: 76-82.

55. Baeuerle PA, Baichwal VR. NF-kappa B as a frequent target for immunosuppressive and anti- inflammatory molecules. Adv Immunol 1997; 65: 111-137.

56. Meduri GU, Headley S, Kohler G, et al. Persistent elevation of inflammatory cytokines predicts a poor outcome in ARDS. Plasma IL-1 beta and IL-6 levels are consistent and efficient predictors of outcome over time. Chest 1995; 107: 1062-1073.

57. Meduri GU, Kohler G, Headley S, Tolley E, Stentz F, Postlethwaite A. Inflammatory cytokines in the BAL of patients with ARDS. Persistent elevation over time predicts poor outcome. Chest 1995; 108: 1303-1314.

58. Golden E, John B, Stentz F, Tolley EA, Meduri GU. Interleukin-8 and soluble intercellular adhesion molecule-1 during acute respiratory distress syndrome and in response to prolonged methylprednisolone treatment. Shock 2000; 13: $42 \mathrm{~S}$.

59. Headley AS, Meduri GU, Tolley E, Stentz F. Infections, SIRS, and CARS during ARDS and in response to prolonged glucocorticoid treatment. Am J Respir Crit Care Med 2000; 161: A378.

60. Meduri GU, Tolley EA, Chinn A, Stentz F, Postlethwaite A. Procollagen types I and III aminoterminal propeptide levels during acute respiratory distress syndrome and in response to methylprednisolone treatment. Am J Respir Crit Care Med 1998; 158: 1432-1441.

61. Carratu P, Quasney MW, Stentz FB, et al. TNF-a and LT-a gene polymorphism in acute respiratory distress syndrome (ARDS). Am J Respir Crit Care Med 2002; 165: A474.

62. Weigelt JA, Norcross JF, Borman KR, Snyder WHD. Early steroid therapy for respiratory failure. Arch Surg 1985; 120: 536-540.

63. Bone RC, Fisher CJ Jr, Clemmer TP, Slotman GJ, Metz CA. Early methylprednisolone treatment for septic syndrome and the adult respiratory distress syndrome. Chest 1987; 92: 1032-1036.

64. Luce JM, Montgomery AB, Marks JD, Turner J, Metz CA, Murray JF. Ineffectiveness of high-dose methylprednisolone in preventing parenchymal lung injury and improving mortality in patients with septic shock. Am Rev Respir Dis 1988; 138: 62-68.

65. Meduri GU. An historical review of glucocorticoid treatment in Sepsis. Disease pathophysiology and the design of treatment investigation. Sepsis 1999; 3: 21-38.

66. Hesterberg TW, Last JA. Ozone-induced acute pulmonary fibrosis in rats. Prevention of increased rates of collagen synthesis by methylprednisolone. Am Rev Respir Dis 1981; 123: 47-52.

67. Hakkinen PJ, Schmoyer RL, Witschi HP. Potentiation of butylated-hydroxytoluene-induced acute lung damage by oxygen. Effects of prednisolone and indomethacin. Am Rev Respir Dis 1983; 128: 648-651.

68. Kehrer JP, Klein-Szanto AJ, Sorensen EM, Pearlman R, Rosner MH. Enhanced acute lung damage following corticosteroid treatment. Am Rev Respir Dis 1984; 130: 256-261.

69. Ashbaugh DG, Maier RV. Idiopathic pulmonary fibrosis in adult respiratory distress syndrome. Diagnosis and treatment. Arch Surg 1985; 120: 530-535.

70. Hooper RG, Kearl RA. Established ARDS treated with a sustained course of adrenocortical steroids. Chest 1990; 97: 138-143.

71. Barber AE, Coyle SM, Marano MA, et al. Glucocorticoid therapy alters hormonal and cytokine responses to endotoxin in man. J Immunol 1993; 150: 1999-2006.

72. Meduri GU, Headley S, Carson S, Umberger R, Kelso T, Tolley E. Prolonged methylprednisolone treatment improves lung function and outcome of unresolving ARDS. A randomized, double-blind, placebo-controlled trial. JAMA 1998; 280: 159-165.

73. Meduri GU, Headley S, Tolley E, Shelby M, Stentz F, Postlethwaite A. Plasma and BAL cytokine response to corticosteroid rescue treatment in late ARDS. Chest 1995; 108: $1315-1325$.

74. Hooper RG, Kearl RA. Established adult respiratory distress syndrome successfully treated with corticosteroids. South Med J 1996; 89: 359-364.

75. Biffl WL, Moore FA, Moore EE, Haenel JB, McIntyre RC Jr, Burch JM. Are corticosteroids salvage therapy for refractory acute respiratory distress syndrome? Am J Surg 1995; 170: 591-595.

76. Meduri GU, Belenchia JM, Estes RJ, Wunderink RG, el Torky M, Leeper KV, Jr. Fibroproliferative phase of ARDS. Clinical findings and effects of corticosteroids. Chest 1991; 100: 943-952.

77. Meduri GU, Belenchia JM, Massie JD, Eltorky M, Tolley EA. The role of gallium-67 scintigraphy in diagnosing sources of fever in ventilated patients. Intensive Care Med 1996; 22: $395-403$.

78. Meduri GU, Tolley EA, Chrousos GP, Stentz F. Prolonged methylprednisolone treatment suppresses systemic inflammation in patients with unresolving acute respiratory distress syndrome. Evidence for inadequate endogenous glucocorticoid secretion and inflammation-induced immune cell resistance to glucocorticoids. Am J Respir Crit Care Med 2002; 165: 983-991.

79. Stentz F, Tolley EA, Headley AS, Chrousos GP, Meduri GU. Mechanisms of NF- $\mathrm{KB}$ and glucocorticoid receptor $(\mathrm{GR} \alpha)$ in activation and regulation of systemic inflammation (SI) in ARDS. Am J Respir Crit Care Med 2001; 163: A450. 